\title{
Enhancing Palm Oil Inventory Control Support Analytic Tools
}

\author{
Fatkhurrahman Manani and Siti Zubaidah Ismail \\ Faculty of Manufacturing \& Mechatronic Engineering Technology, College of Engineering Technology, Universiti Malaysia Pahang, 26600 Pahang, \\ Malaysia.
}

\begin{abstract}
Product-Service System (PSS) inventory control in Malaysian palm oil industry is a blend of product or services that offer a good worth in regards to economics and also environment. This paper intends to establish a support analytic device for implementation in the palm oil industry. Many smallholder businesses do not have any kind of supply systematic record-keeping to keep the supply in a respectable operating. The existing technique of figuring out supply takes a yearly physical inventory by comparing the real inventory with document levels. This method is a pricey as well as lengthy effort. In this paper, an inventory control web-based application device was developed to meet customer demand and methodical record management is significant to have respectable tracking and also analysis as part of being effective. This tool will certainly help the firm to save the main stock data-based on collected information and also to monitor the motion of the stocks to ensure that whatever is controlled as well as in great order. This tracking process makes it much easier for firms to decide and also for forecasting for products and services in palm oil plantation.
\end{abstract}

\section{ARTICLE HISTORY}

Revised: $18^{\text {th }}$ March 2021

Accepted: 19th March 2021

\section{KEYWORDS}

Product-Service System (PSS)

Inventory Control

Web-Based Application

\section{INTRODUCTION}

Product-Service System (PSS) is a mix of product or services to satisfy consumer demands which is really valuable for firms in administration facets to maintain sustainability and to renew and also enhance existing systems likewise has actually been established as a new business version due to its deal a great value in terms of business economics and environment [1-3]. In the modern-day manufacturing age, many business in recent years are getting interested to establish PSS and providing it to their customers. However, it has actually been discovered that study on PSS in agriculture especially the hand oil business is limited.

The palm oil farming sector just recently needs to try to find a new method to attain a long-term affordable benefit to remain successful and also no loss [4]. PSS is a system where several sector gamers give each various other's products and services [5]. PSS idea is to support companies to achieve servitization and it is taken into consideration as serviceoriented reasoning to enhance product value also increase in regards to customer-producer connection [6]. PSS is a link in between product and service that supplies value in use which creating even more performance and also lowering the effect on the atmosphere [7].

Inventory control in agriculture is about the standard expertise of monitoring in terms of regulating and also taking care of perishability products [8]. Agriculture sectors constantly deal with excellent managerial decisions to gain efficiency as well as competition to stay pertinent in the marketplace. The characteristics of agricultural products that are always appropriate to ecological problems such as worldwide warming resulting in top monitoring requirement to play an efficient function in inventory control due to its importance in a systematic farm. The theory of inventory control, especially on agriculture items, needs a lot more consideration due to its unique characteristics such as unpredictable supply as well as price as well as inconsistent need.

This research focus on PSS inventory control in palm oil plantations into a single system by developing inventory control software program as a tool to managed products and services in an organized method for enhancing competitiveness. The developed software is able to assists the company to monitor, forecast, and decision to make. The integration between the products (e.g seeds, fertilizer) and services( transportation, consulting) will certainly create a system that will support the business in achieving excellent palm oil industry practice. The application of PSS inventory control in palm oil farming needs to be recognized deeply the procedure and the impact of the execution. The quantity of stock has a straight impact on the responsiveness and also effectiveness of procedures of the business. Stock control plays an important part in managing stock to make sure that the stock level of palm oil products need to be low yet sufficient to meet the order of the handling device to stop any loss as a result of the damaged items because of kept also long. The system provides useful information for top management to make more accurate and precise decisions. 


\section{RELATED WORK}

Product-Service System (PSS) is a mix of product or services that supply a good worth in regards to economics as well as environment [1-2]. PSS is really useful for companies in monitoring facets to maintain sustainability and at the very same time to renew and boost existing systems [9]. In addition to that, lots of companies over the last few years are getting interested to create PSS and providing it to their clients.

Inventory control is the center stage of business presence, survival, development, as well as sustainability. It was taken into consideration a road map that provides direction to brand-new company for making decisions concerning the administration of cash money, raw materials, completed products, and receivables. Besides, it also was disclosed that the dangers associated with everyday organization shipments are high. Efficient and systematic inventory management plays a huge function in establishing the success of the firms operation and has a straight effect on improved firm's efficiency [10]. Many companies as well as supply chains need to run efficiently.

Data show that Malaysian palm oil inventory such as Fresh Fruit Number (FFB) and also Crude Hand Oil (CPO) have actually decreased $12.2 \%$ to 86.33 million tones as well as $13.2 \%$ to 17.32 million tones [11]. This shows that the storage of an inventory at an optimum level leads to high efficiency to fulfill the needs of the marketplace without excessive stock. However, the present scenario of the tiny palm oil business in Malaysia displays that they do not have any kind of systematic inventory record-keeping. Farmers who have an excellent as well as systematic record tracking have a tendency to be much more efficient than the farmers without [12]. The integration between the products (e.g seeds, plant food) as well as services (i.e.: transportation, consulting) will certainly create a system that will help the business in attaining excellent palm oil market technique.

\section{INVENTORY WEB-BASED APPLICATION}

For this research, there are numerous primary features applied in this this inventory web-based application system to assist the firm manages its stock control much more efficiently. For safety facets, there is a login web page just for confirmation individuals to access it. There likewise have the inventory manager, monitoring tool, detailing tool, costing tool in the system. Each of these has a different feature relying on the requirements of the company. All organizations or companies involving products should concern inventory control to keep inventory in a correct quantity to make sure that businesses able to fulfill customer need with no disturbance. It is vital to have a good supply control system as well as stock tool which can help in stock management therefore avoiding massive waste and losses.

To develop a functional software application system, several methods and also arrangements have to be planned as well as proved which is one of the most ideal software program that could be used for the inventory tool. The web-based software that would certainly be used for this application system have to be able to stand alone or independently, have the ability to save a huge amount of data, be able to make some projections to help in decision production, and also have good protection. After doing examining the most optimal software that would be made use of in this application system is Java servlet as the user interface as well as MySQL server as the database. Therefore, this study is going to create software online applications utilizing Netbeans IDE 8.2 as a system and XAMPP as a port.

The stock web-based application process begins with downloading the Netbeans IDE 8.2 and XAMPP as a system as well as followed by installing both on the computer. It is a cost-free as well as open-source platform Integrated Advancement Environment (IDE) for designer particularly students in creating software program java online applications. The researcher selects to made use of Netbeans due to the fact that it was just utilized the visuals user interface (GUI) device to style by just dragging the components. When dragging is full the coding operation is started to make sure that each element functions as preferred by the designers. When finished creating a new task, the next step was to create a brand-new JFrame which is a structure that aids in creating and also developing an icon (GUI) by simply going down and also dragging parts like panel, switch, tag, table, etc. Figure 1 shows the flow of processes in developed inventory software.

Researcher can develop designs based on their needs with simply a drop as well as drag. The coding procedure comes after the design is finished and this is a really critical component. The operating and screening procedure require to be done for each coding component that has actually been efficiently placed. If there is no error while doing so it is considered effective and the procedure must be duplicated for every component of the job. If there is an error during testing then the coding procedure must be repeated until it is successful.

There are numerous main functions carried out in this inventory web-based application system to help the business manages its inventory control a lot more efficiently. For protection aspects, there is a login page just for confirmation people to access it. For instance, the supervisor keeping track of device, detailing tool, setting device in the system. Each of these has a different function depending on the needs of the business. All services or companies entailing products must issue inventory control to maintain supply in a proper quantity to ensure that businesses able to satisfy customer demand with no disturbance. It is important to have a great supply control system as well as inventory device which can assist in supply management hence preventing huge waste as well as losses. To establish a useful software application system, several strategies and setups have to be prepared as well as verified which is one of the most appropriate software applications that may be used for the supply device. The web-based software application that would certainly be used for this application system need to have the ability to stand alone or individually, have the ability to save a big quantity of data, be able to make some forecast to assist in decision making, and have great security. 


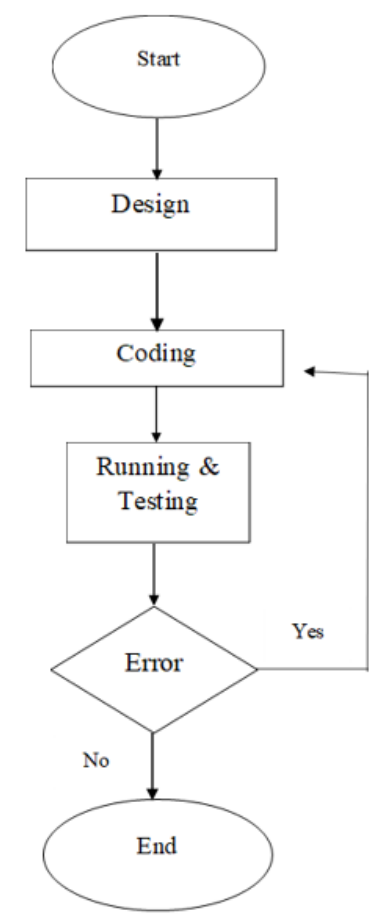

Figure 1. Inventory Web-Based Application Flowchart

After doing evaluating the most optimum software program that would certainly be made use of in this application system is Java servlet as the interface and MySQL server as data source. Consequently, this research is likely to develop software application online applications making use of Netbeans IDE 8.2 as a platform and also XAMPP as an adapter. Both Net-beans IDE 8.2 is and also XAMPP are open source systems that can be utilized for free for those who are developing software program. To start with, creating the online database by using MySQL and also phpMyAdmin server which sustained in XAMPP. After that continual the step with creating and creating the interface of the supply tool by using Java servlet. Programming as well as creating the coding to connect the MySQL web server with the Java servlet.

To establish a useful software application system, several strategies and setups have to be prepared as well as verified which is one of the most appropriate software applications that may be used for the supply device. The web-based software application that would certainly be used for this application system need to have the ability to stand alone or individually, have the ability to save a big quantity of data, be able to make some forecast to assist in decision making, and have great security.

After doing evaluating the most optimum software program that would certainly be made use of in this application system is Java servlet as the interface and MySQL server as data source. Consequently, this research is likely to develop software application online applications making use of Netbeans IDE 8.2 as a platform and also XAMPP as an adapter. Both Net-beans IDE 8.2 is and also XAMPP are open source systems that can be utilized for free for those who are developing software program. To start with, creating the online database by using MySQL and also phpMyAdmin server which sustained in XAMPP. After that continual the step with creating and creating the interface of the supply tool by using Java servlet. Programming as well as creating the coding to connect the MySQL web server with the Java servlet.

Lastly, troubleshooting the supply tool up until it totally running as expected. By going to develop this software program, it is expected to aid the palm oil markets in managing their stock in an optimum method.

\section{RESEARCH OUTCOMES}

This inventory control works to track and trace for every set of the inventory which is referred to as past as well as current details. It potentially will help the company to keep track of the activity of the stocks to make sure that every little thing is under control and in excellent order. This tracking process turn makes it simpler for business to make product preparation and also even for forecasting strategies. Tracking and tracing inventory is an important aspect due to the company needs to know the current status of the inventory before making any decisions. The monitoring process enables top management to make forecasts of company production and planning based on its current inventory status. It is like a check and balance process for the company to either increase its production or decreases it. Very important for the company not to have overstock inventory due to its hidden costs such as additional warehousing, organizing, and damage. The top management has to consider how many mature seedlings are needed for replanting before it can be sold and making some profit from it. For Fresh Fruit Bunch (FFB) inventory, the company has to ensure the FFB should deliver to the milling process immediately after harvesting to prevent yield drop. For weeding and manuring, the company will refer to the analysis done by the ergonomist and will order accordingly. Figure 2 shows the current status of the inventory 
based on each batch. The figure provides data for the current situation based on real-time inventory levels. From this data, the company can make a comparison to the previous data.

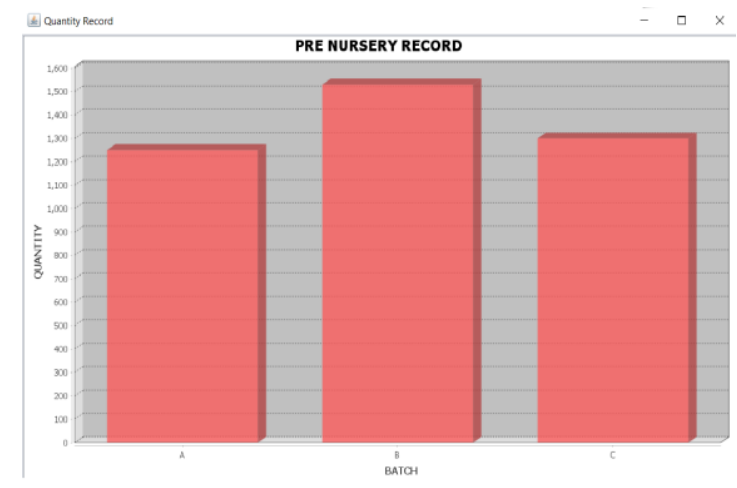

Figure 2. Current Status Analysis

The data including the date of entry for each batch, the expected output date for each batch, and the expected date for each new batch. The actual output date for each inventory should not differ from the expected output date cause the delays will affect the company's planning. This tool also contains the actual quantity for each batch, total damage that occurred during the process, and expected output number. The number of damaged products is something that should be minimized to maximize profit. Many factors contribute to damage such as pests, weather, etc. Top companies management needs to look at all aspects of mitigating this damage and at the same time to maximize company profitability. At the same time, companies can think of getting rid of processes or elements that do not bring sufficient outcomes. Although it may seem small, it can also have an impact on the company's performance if left without any action.

This tool will keep top management always in an alert situation about the company's inventory due to its nature. Delays in the workflow cannot be tolerated because they will affect in terms of the quality of the product consequently increasing the unneeded expenses. The presence of this tool will make top companies management more prepared when an inventory expects to be brought in and or has reached its expected output date and needs to be shipped immediately to the next destination. In other words, this tool acts as a forecast based on previous data. This will assist companies in terms of planning and budgeting. Good preparation should be possible when the right information is known in advance. All the processes are expected to go smoothly and without hindrance, and there is no reason for something to happen unless something beyond expectations. This tool creates a good coordination process between product and transportation management. Figure 3 shows the detailed data for each batch which delivers input to the company to ana-lyze which batch is getting the best result.

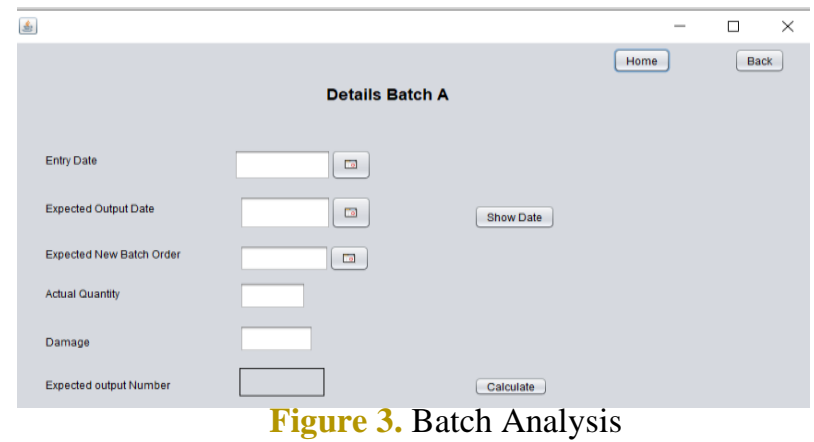

This allows top management to make the best pricing choices according to the needs and capabilities of the company. Significant for the company to know the cost before fixing the selling prices to set profitable prices. Knowledge of the exact cost will be the key for top management to ensure all costs are covered. The latest market information is essential for a company to meet the changing market demands and trends. This tool also allows companies to set their budget limits to ensure that products do not exceed their budget. There are various costs that companies need to consider such as fixed cost and variable cost. Very important for a company to save money and make money by knowing its total cost. Variable costs constantly changing need to be updated for companies to set the ideal cost for their products. A company must remain profitable so that its business remains relevant and sustainable. From the profit margin company, it is advisable to do some analysis to see the growth of the business and how well the company is operating. Figure 4 shows the detailed data for each batch which delivers input to the company to ana-lyze which batch is getting the best result. 


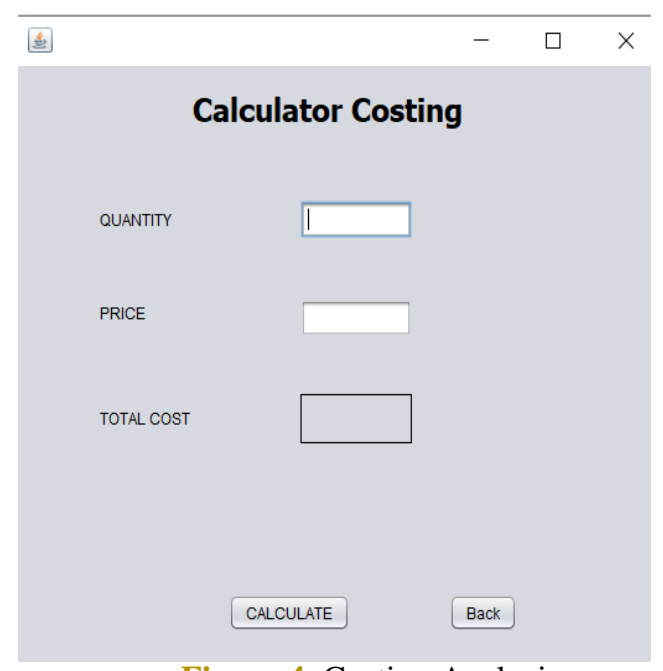

Figure 4. Costing Analysis

\section{CONCLUSION}

This paper has delivered a significant lead to the development of PSS Inventory Control web-based application for testing and evaluation of the system's parameters in the Malaysian palm oil industry. This system supposedly improved current inventory management by delivering analysis on current status, each batch, and cost. A better internet facility, together with a boosted safety level is required throughout the use of application so that it can be used fully utilized.

\section{ACKNOWLEDGEMENT}

This research would not have been possible without the financial support given by the Universiti Malaysia Pahang via RDU180293. Neither would it have been possible without the support, time, and knowledge provided by the collaborating industrial company. The views expressed in this paper are those of the authors.

\section{REFERENCES}

[1] Baines, T. S., Lightfoot, H. W., Evans, S., Neely, A., Greenough, R., Peppard, J., ... Wilson, H. (2007). State-of-the-art in product-service systems. Proceedings of the Institution of Mechanical Engineers, Part B: Journal of Engineering Manufacture. https://doi.org/10.1243/09544054JEM858.

[2] Chen, C. (2018). Guidance on the Conceptual Design of Sustainable Product-Service Systems. https://doi.org/10.3390/su10072452

[3] Fargnoli, M., Costantino, F., Gravio, G. Di, \& Tronci, M. (2018). Product service-systems implementation : A customized framework to enhance sustainability and customer satisfaction. Journal of Cleaner Production, 188, 387-401. https://doi.org/10.1016/j.jclepro.2018.03.315

[4] Ismail, S. Z. B., Morton, S. C., Harding, J. A., \& Michaelides, R. (2015). Product-Service System in inventory control: A new paradigm? IEOM 2015 - 5th International Conference on Industrial Engineering and Operations Management, Proceeding. https://doi.org/10.1109/IEOM.2015.7093775

[5] Durugbo, C., Bankole, O. O., Erkoyuncu, J. a., Tiwari, A., Alcock, J. R., Roy, R., \& Shehab, E. (2010). Product-Service Systems across Industry Sectors: Future Research Needs and Challenges. CIRP IPSS Conference, 535-542. Retrieved from http://dspace.lib.cranfield.ac.uk/handle/1826/4709

[6] Xing, K., \& Ness, D. (2016). Transition to Product-service Systems: Principles and Business Model. In Procedia CIRP. https://doi.org/10.1016/j.procir.2016.03.236

[7] Costa, N., \& Patr, L. (2018). Design approaches, 55. https://doi.org/10.1016/j.destud.2017.09.002

[8] Behzadi, G., Justin, M., Sullivan, O., Lennon, T., \& Zhang, A. (2018). Agribusiness supply chain risk management : A review of quantitative decision models R. Omega, 79, 21-42. https://doi.org/10.1016/j.omega.2017.07.005

[9] Fargnoli, M., Costantino, F., Gravio, G. Di, \& Tronci, M. (2018). Product service-systems implementation : A customized framework to enhance sustainability and customer satisfaction. Journal of Cleaner Production, 188, 387-401. https://doi.org/10.1016/j.jclepro.2018.03.315

[10] Atnafu, D., Balda, A., \& Liu, S. (2018). The impact of inventory management practice on firms ' competitiveness and organizational performance: Empirical evidence from micro and small enterprises in Ethiopia. Cogent Business \& Management, 5(1), 1-16. https://doi.org/10.1080/23311975.2018.1503219

[11] Nambiappan, B., Palm, M., \& Board, O. (2018). MALAYSIA : 100 YEARS OF RESILIENT PALM OIL ECONOMIC PERFORMANCE, (April). https://doi.org/10.21894/jopr.2018.0014

[12] Fadzim, W. R., Aziz, M. I. A., \& Jalil, A. Z. A. (2017). Determinants of technical efficiency of cocoa farmers in Malaysia. International Journal of Supply Chain Management, 6(1), 254-258. 